九州大学学術情報リポジトリ

Kyushu University Institutional Repository

\title{
Analyzing the Impacts of a Deep-Learning Based Day-Ahead Residential Demand Response Model on The Jordanian Power Sector in Winter Season
}

\section{Shaqour, Ayas}

Energy and Environmental Systems Laboratory, Interdisciplinary Graduate School of Engineering Sciences, Kyushu University

Farzaneh, Hooman

Energy and Environmental Systems Laboratory, Interdisciplinary Graduate School of Engineering Sciences, Kyushu University

https://doi.org/10.5109/4738595

出版情報 : Proceedings of International Exchange and Innovation Conference on Engineering \& Sciences (IEICES). 7, pp. 247-254，2021-10-21. 九州大学大学院総合理工学府 バージョン:

権利関係 : 


\title{
Analyzing the Impacts of a Deep-Learning Based Day-Ahead Residential Demand Response Model on The Jordanian Power Sector in Winter Season
}

\author{
Ayas Shaqour ${ }^{*}$, Hooman Farzaneh ${ }^{1}$ \\ ${ }^{1}$ Energy and Environmental Systems Laboratory, Interdisciplinary Graduate School of Engineering Sciences, Kyushu \\ University, Japan. \\ *Corresponding author email: shaqour.ayas.886@s.kyushu-u.ac.jp
}

\begin{abstract}
In this paper, a detailed analysis of the impact of a day-ahead residential demand response model on the winter season of Jordan's power sector is presented and discussed. The model used is based on a deep neural network that was trained on four years of Jordan's electrical demand data and a profit-based day-ahead demand response optimization. The day-ahead demand response model was established based on the predicted day-ahead demand and a demand response model conducted by Jordan's Grid operator $(G O)$ being NEPCO to reduce its energy costs from the power Generator (PGs) by applying a day-ahead peak period pricing scheme on the service providers (SPs). The results of applying the DR model on the winter season showed that a potential peak reduction of $4.49 \%$ to $8.19 \%$ could be achieved as well as a cost reduction of $64,263 \$$ to $265,411 \$$ per day.
\end{abstract}

Keywords: Deep Neural Networks, Demand Response, Electricity market, Price Elasticity Matrix of Demand, Jordan

\section{INTRODUCTION AND REVIEW}

With the fast growth of the global population and economies, especially in developing countries, the energy demand that needs to be supplied is growing fast at $1 \%$ and $5 \%$ for both developed and developing countries, respectively[1]. As Jordan's energy demand is facing an annual growth rate of $3 \%$, the recent big surge of refugees from Syria, and heavy reliance on imported energy resources, the Jordanian government has committed to undergoing reforms to its electrical power sector[2][3]. The government initiated the National Energy Efficiency Action Plan (NEEAP) in 2013 to reach an energy-saving level of $20 \%$ and a $10 \%$ of renewable energy share in the power mix by 2025 and the Automatic Electricity Tariff Adjustment Mechanism (AETAM) to reduce the losses and heavy loans caused by the expensive imported fuels[4]. Due to the government's dedication to growing its renewable sector, decrease reliance on energy imports, and increase its energy self-sufficiency rate, renewable energy reached $1470 \mathrm{MW}$ in power capacity by 2019 , which accounted for almost one-quarter of the total capacity of energy generation in Jordan with around $75 \%$ being solar energy. Although, the large increase in renewable energy characterized by stochasticity and being nondispatchable has raised the burden and complexity of optimizing demand-supply and unit commitment scheduling for the GO[5][6]. Fig. 1 shows the hourly power demand for a day in December-2019 with the renewable generation of wind and solar. It can be depicted from the figure that there is a rapid decrease of solar energy between 15:00 and 17:00, while at the same time, a fast ramping of the evening peak demand between 15:00 and 18:00. Hence, the GO needs to compensate for approximately $992 \mathrm{MW}$ of power in 3 hours which accounts for $44 \%$ of the average load of that day. This is done by using very costly and fast ramping energy generators, where a reduction in the peak demand can highly reduce the economic burden on the GO in the peak time.

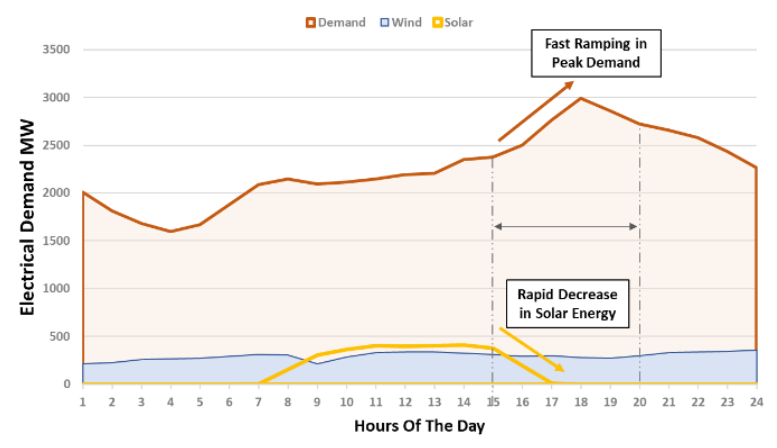

Fig. 1 Power demand and renewable generation on the $12^{\text {th }}$ of December 2019

To achieve a reduction in peak demand and influence consumers to shift their demand outside of the peak period, a demand response (DR) system was proposed[7] DR systems allow the participation of different types of electrical demand end consumers to contribute to the power market and balancing the electrical demandsupply. The GOs and SPs influence the participation of end consumers by either dynamically changing the price of electrical energy at different hours of the day or by providing different forms of incentives to the consumers to shift their demands away from peak periods and towards periods of lower demand. Hence, DR systems can increase the GO's flexibility in balancing the supplydemand at different hours of the day, especially in mitigating the impact of the high ramping demand at peak periods under high renewable penetration, thus, enabling more optimized Grid management [8][9][10]. The Jordanian power sector has already implemented a DR pilot project to the principal consumer of the GO being mainly large industries which resulted in 6 million $\$$ of cost-saving for the GO in terms of direct gains, with the indirect benefits of a more optimal power grid operation. The project report recommended future expansion to the residential sector, which is now more prevalent under the rapid installments of smart meters in Jordan that can enable DR systems.

Both building and residential energy demand hold a substantial share of the total energy demand worldwide[11][12]. Domestic and governmental 
buildings accounted for almost $46.12 \%$ of the electrical demand in Jordan in 2019[13]. Hence, a DR system that targets the residential sector can be a great asset and opportunity for the GO to optimize the daily demand curve and achieve more optimal grid operation, especially at peak periods by reducing peak demand. Tawalbeh et al. investigated the use of Time of Use (TOU) pricing in Jordan's residential sector and showed that a peak demand energy of $3.5 \mathrm{kWh}$ could be achieved [14]. Jarad and Ashhab showed that a cost saving of $20 \%$ and energy consumption reduction of $15 \%$ could be achieved through better energy efficiency measures for residential consumers in Jordan[15].

Recently, many studies investigated the development of residential DR programs. Cosmo et al. investigated the coupling of ToU DR with in-home information display units on 5000 residential households in Ireland, where they showed its significant potential in achieving energy demand reduction, especially in peak electrical demand periods[16]. Wang et al. simulated and compared ToU and incentive-based DR on 100 residential households. Their results showed that under the participation of $60 \%$ of the households in the ToU DR, a $24 \%$ in energy generation cost can be attained. However, at higher participation rates, the ToU DR showed less performance than the incentive-based DR[17]. Mengelkamp et al. applied a price-based dynamic DR on a simulated residential energy market of 100 households. Their model showed that the DR program can improve the local self-sufficiency by $16 \%$ and achieve a peak reduction of $40 \%$ [18]. Yoon et al. presented a simulation for 2 residential buildings in Texas, USA, under two different real-time DR pricing schemes that target HVAC usage. Their results depicted that energy costs can be reduced by $10.8 \%$, and an annual reduction of peak load and HVAC energy consumption at $24.7 \%$ and $4.3 \%$, respectively, can be achieved[19]. Dupont et al. analyzed the impact of DR on the residential sector of Belgian based on a two-stage modeling approach combining both a real-time hourly simulation and day-ahead unit commitment under two alternative generation technology scenarios. Their results present a general reduction in power generation cost due to peak and midpeak power plants usage, increased system reliability, and reduced emission levels.
In our previous work, a detailed day-ahead DR model was developed for the residential sector of Jordan's power sector, where a precise day-ahead demand prediction using a deep neural network was introduced, and a detailed day-ahead demand response model was discussed[7]. In this work, we present a detailed analysis of the impact of the proposed model on the winter month of December 2019 as follows:

1. A detailed analysis of the days with the highest demand and the potential of DR on reducing their peak demand.

2. The daily impacts of demand response for December are analyzed based on the best- and worst-case scenarios of applying the proposed demand response from the preceptive of: Peak demand reduction, load factor improvement, and generation cost saving.

3. The impact of high-performing day-ahead demand prediction on forecasting the DR policy implications on the following day's demand.

The rest of the paper is depicted as follows: Section 2 introduces the material and methods used in terms of DR modeling, Power Sector's optimization model, dayahead prediction modeling, power plant dispatch scenario, and the price elasticity of demand (PEMD) analysis. Section 3 discusses the application of the model in the month of December-2019 with extensive numerical results related to different performance metrics of DR. Section 4 presents a discussion of the results and Section 5 concludes the paper.

\section{Material and Methods}

Jordan's electrical sector is depicted in Fig. 2, which shows the PSs, GO represented by the national electric power company (NEPCO), the SPs (EDCO, IDECO, and JEPCO), principal consumer (PCs), and end consumers. The Ministry of Energy and Mineral Resources (MEMR) governs the long-term strategy of the electricity sector, while the Energy and Mineral Regulatory Commission (EMRC) provides licenses and regulations, and establishes laws and tariffs to the electricity sector[20]. Under a residential DR, the GO applies optimized dynamic pricing schemes on the SPs, which translates into their end consumers in a way that influences their demand patterns, especially at peak periods.

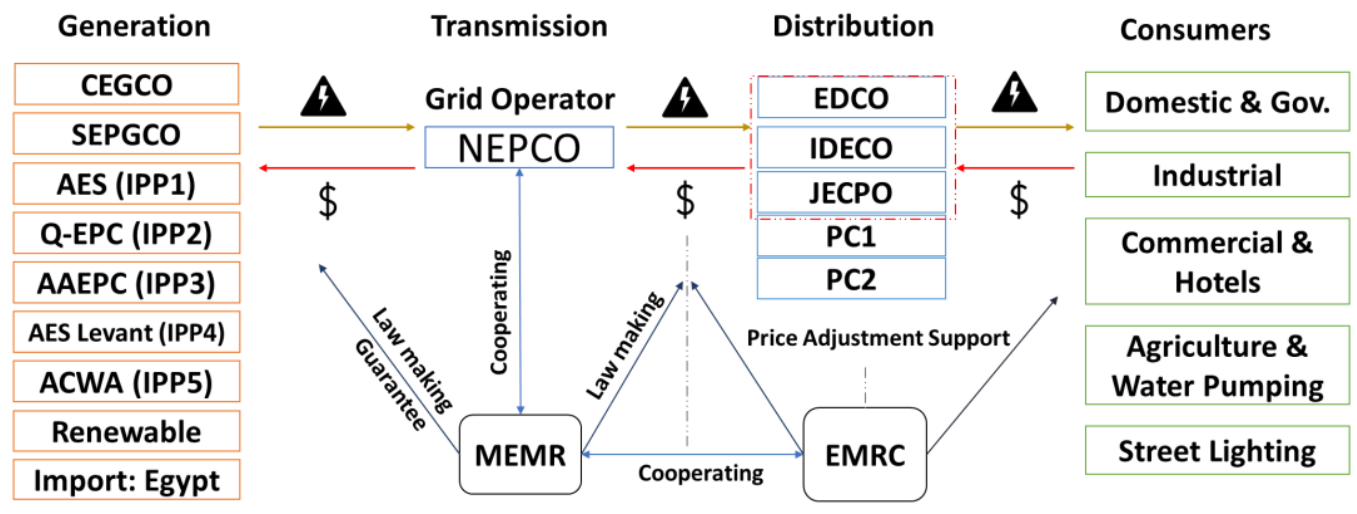

Fig. 1 Electricity Sector of Jordan - 2019 [7] 


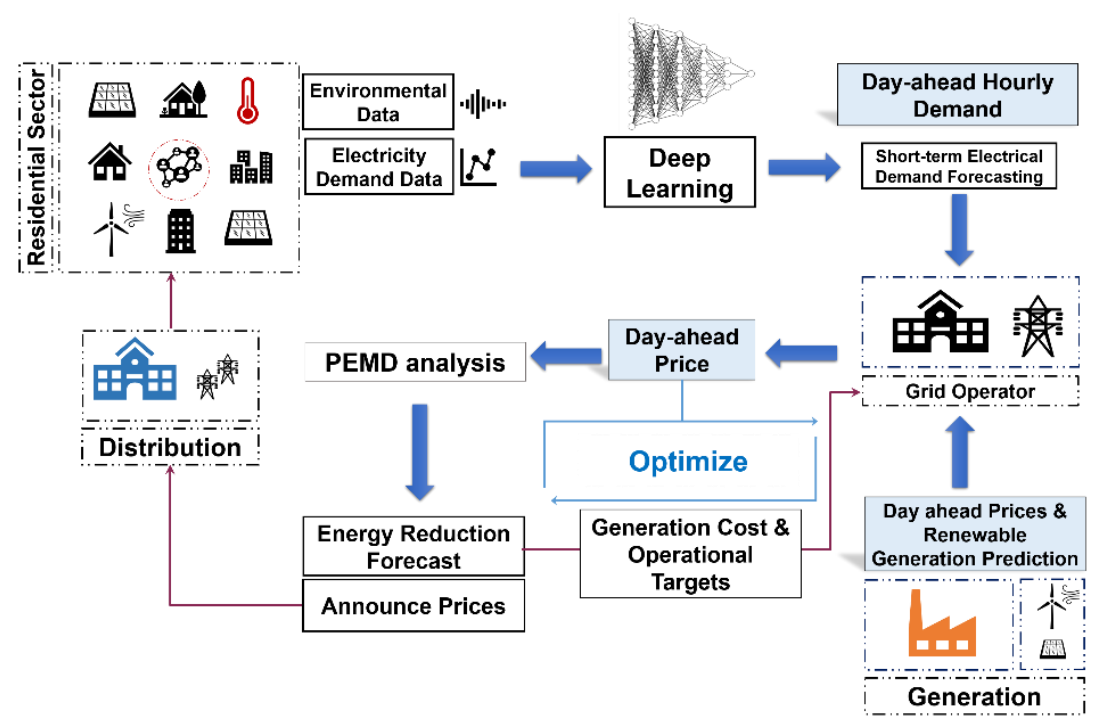

Fig. 3 Day-ahead Residential Demand Response Scheme[7]

\subsection{Day-ahead Residential Demand Response modeling}

The proposed day-ahead residential demand model can be seen in Fig. 3. The GO first predicts the hourly dayahead electrical demand of the residential sector, collects the day-ahead scheduled unit commitment data and renewable energy generation predictions. Then by using the PEMD and optimizing different price schemes for the peak period, the DR impact is predicted in terms of different operating targets, such as peak demand reduction, generation cost savings, load factor improvements, and profit expected to increase. Once the optimal prices are calculated, they are announced to the Service providers at the start of the next day and the expected impact of the DR on the day-ahead demand is used to further optimize the day-ahead unit commitment scheduling. The profit optimization model used by the $\mathrm{GO}$, considering its energy purchased from the PSs and energy sold to the SPs, is depicted as follows[7]:

$$
\begin{aligned}
\operatorname{Max} \sum_{d=1}^{D} \sum_{h=1}^{H}( & \sum_{c=1}^{C} I_{c, h}\left(s p_{c, h}, d s_{c, h}\right) \\
& \left.-\sum_{p s=1}^{P S} C_{p s, h}\left(b p_{p s, h}, d p_{p s, h}\right)\right) \\
& +\sum_{c=1}^{C} P C I_{C}\left(d p_{c}, d p p_{c}\right)
\end{aligned}
$$

The model represents the monthly profit of the GO, where $I_{c, h}$ depicts the income from each of the bulk consumer $c$ at each hour $h$, which depends on the amount of demand sold $d s_{c, h}$ for each bulk consumer at each hour and the selling price $s p_{c, h}$. The second part represents the liability of the hourly cost of purchasing energy $C_{p s, h}$ from each power supplier $p s$ based on the buying price $b p_{p s, h}$ and demand purchased $d p_{p s, h}$. The last part, which is not considered in the proposed model, depicts the monthly peak cost-income $P C I_{C}$ from each bulk consumer, which is a function of the monthly demand peak $d p_{c}$ at specified peak times and the demand peak pricing $d p p_{c}$. The GO through DR can impact the day-ahead hourly demand per bulk consumer $\boldsymbol{d} \boldsymbol{s}_{\boldsymbol{c}, \boldsymbol{h}}$ by changing the hourly selling price $\boldsymbol{s} \boldsymbol{p}_{\boldsymbol{c}, \boldsymbol{h}}$ in a way that reduces the peak demand as follows[7]:

$$
\begin{gathered}
d s_{c, h}=d s_{c, h}^{0}\left[1+\varepsilon_{h} \frac{s p_{c, h-} s p_{c, h}^{0}}{s p_{c, h}^{0}}+\sum_{h=1,}^{24} \varepsilon_{h}^{\prime} \frac{s p_{c, h-} s p_{c, h}^{0}}{s p_{c, h}^{0}}\right] \\
s p p_{c, h, \text { Min }} \geq s p_{c, h} \geq s p p_{c, h, \text { Max }}
\end{gathered}
$$

Equation 2 represents the impact on the original demand $d s_{c, h}^{0}$, of the new selling price $s p_{c, h}$ for bulk consumer c at an hour $h$ relative to the original price $s p_{c, h}^{0}$ of that hour as well as the change in price in other hours of the day. $\varepsilon_{h}$ represents the self-elasticity which related the change in price at a certain hour to the demand change of that hour, while $\varepsilon_{h}^{\prime}$ represents the cross-elasticity that captures the effect of a change in the price of other hours of the day on that hour. Equation 3 depicts the selected minimum and maximum range of the new price. The self and cross elasticates represent the core of DR analysis and is related to the PEMD which is formulated as follows [21]:

$$
\left[\begin{array}{c}
\Delta d s_{c, 1} / d s_{c, 1}^{0} \\
\vdots \\
\Delta d s_{c, i} / d s_{c, i}^{0} \\
\vdots \\
\Delta d s_{c, 24} / d s_{c, 24}^{0}
\end{array}\right]=\left[\begin{array}{ccccc}
\varepsilon_{1,1} & \cdots & \varepsilon_{1, j} & \cdots & \varepsilon_{1,24} \\
\vdots & & & & \vdots \\
\varepsilon_{i, 1} & \cdots & \varepsilon_{i, i} & \cdots & \varepsilon_{i, j 24} \\
\vdots & & & \vdots \\
\varepsilon_{24,1} & \cdots & \varepsilon_{24, j} & \cdots & \varepsilon_{24,24}
\end{array}\right] *\left[\begin{array}{c}
\Delta s p_{c, 1} / s p_{c, 1}^{0} \\
\vdots \\
\Delta s p_{c, i} / s p_{c, i}^{0} \\
\vdots \\
\Delta s p_{c, 24} / s p_{c, 24}^{0}
\end{array}\right]
$$

The PEMD represented by the $\varepsilon$ matrix related the change of the price in every hour of the day to the change of demand at every hour, where the diagonal reprinted by $\varepsilon_{i, i}$ depicts the self-elasticity and the off-diagonals represent the cross-elasticates.

\subsection{Day-ahead demand prediction modeling}

To run the day-ahead DR model, the day-ahead hourly demands should be obtained. In this work and relating to our previous work[7], a deep neural network (DNN) was trained on four years of the hourly electrical demand of Jordan's power sector was used. Fig. 4 shows the typical 
structure of a neural network consisting of the input layer representing the input features correlated to the predicted output, the hidden layers made on neurons, and the output layer consisting of the variable to be predicted[21]. Neural networks (NNs) are powerful machine learning algorithms that contain neurons depicted by weights, biases, and non-linear activation functions. Their complex interconnections can model complex non-linear relations between an output variable and its correlated feature variables[22].

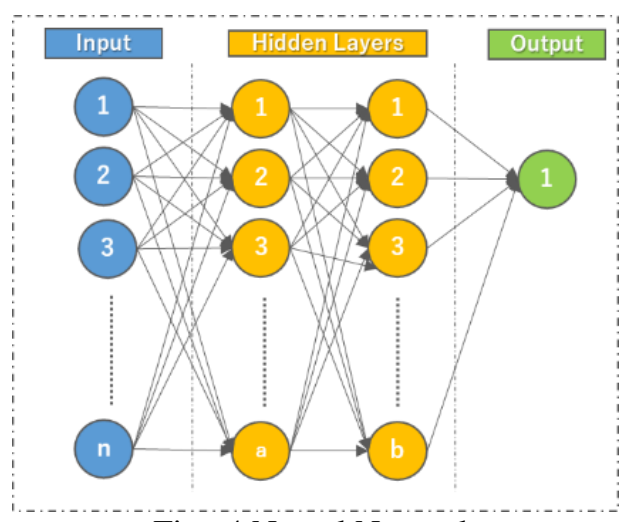

Fig. 4 Neural Network

Based on a systematic feature analysis and engineering, Table 1 shows the selected input feature variables to the DNN to predict the day-ahead hourly electrical demand at any selected hour.

Table 1 Selected input feature variables to the DNN [7]

\begin{tabular}{|c|c|c|c|}
\hline Type & & Input & Range \\
\hline \multirow{13}{*}{$\begin{array}{l}\text { Exogenous input } \\
\text { features related to } \\
\text { demand at the hour to } \\
\text { be predicted }\end{array}$} & 1 & $\begin{array}{c}\text { Morning Peak- } \\
\text { Load Temperature } \\
{ }^{\circ} \mathrm{C}\end{array}$ & $4-42$ \\
\hline & & Evening Peak- & \\
\hline & 2 & $\begin{array}{c}\text { Load } \\
\text { Temperature }{ }^{\circ} \mathrm{C}\end{array}$ & $2-37$ \\
\hline & 3 & $\begin{array}{l}\text { Minimum Load- } \\
\text { Temperature }{ }^{\circ} \mathrm{C}\end{array}$ & $-1-34$ \\
\hline & 4 & Hour of the day & $1-24$ \\
\hline & 5 & Day of the Year & $1-366$ \\
\hline & 6 & Week of the Year & $1-53$ \\
\hline & 7 & Normal Day & {$[0,1]$} \\
\hline & 8 & National Holiday & {$[0,1]$} \\
\hline & 9 & Ramadan & {$[0,1]$} \\
\hline & 10 & Sunday & {$[0,1]$} \\
\hline & & & {$[\mathbf{0 , 1}]$} \\
\hline & 16 & Saturday & {$[0,1]$} \\
\hline \multirow{12}{*}{$\begin{array}{l}\text { Endogenous input } \\
\text { features related to the } \\
\text { demand at previous } \\
\text { hours (Lagged Demands } \\
\text { (LD)) }\end{array}$} & 17 & LD (-24 hours) & $\begin{array}{c}1195- \\
3380\end{array}$ \\
\hline & 18 & LD (-25 hours) & \\
\hline & 19 & LD (-26 hours) & \\
\hline & 20 & LD ( -48 hours) & \\
\hline & 21 & LD (-49hours) & \\
\hline & 22 & LD (-50 hours) & \\
\hline & 23 & LD (-168 hours) & \\
\hline & 24 & LD (-169 hours) & \\
\hline & 25 & LD (-170 hours) & \\
\hline & 26 & LD (-192 hours) & \\
\hline & 27 & LD (-193hours) & \\
\hline & 28 & LD (-194hours) & \\
\hline
\end{tabular}

The initial data was split into approximately $90 \%$ training data, to train the model, $5 \%$ validation data to tune the model, $5 \%$ testing data, and the last month of 2019 to test the model generalization. The tunning process resulted in a DNN with 4 hidden layers with 1024, 512, 256, and 128 neurons, respectively, from the first to last layer. The elu was selected as the activation function, and adam was used as the optimization algorithm of the neural network. Generalization of the network was achieved by applying a dropout probability of 0.1 to the first two layers and a $0.18 \mathrm{~L} 2$ regularization for all the layers coupled with early stopping[7]. As a result, the model achieved a very low mean absolute percentage error (MAPE) of $1.205 \%$, $1.356 \%$, and $1.411 \%$ on the training, validation, and testing datasets, respectively, and $2.03 \%$ on the final month of 2019.

\subsection{Power dispatch modeling}

The dispatch model depicts the available power plants based on a unit-commitment analysis conducted daily by the GO. For this research, Table 2 shows a selected power plants mix based on a real scenario provided by NEPCO on the available power plants on Sunday, the $8^{\text {th }}$ of December 2019[13].

Table 2 Dispatch Scenario of the 8th of December 2019[7]

\begin{tabular}{|c|c|c|c|c|}
\hline Unit & Name & $\begin{array}{c}\text { Cost } \\
(\mathrm{JD} / \mathrm{M})\end{array}$ & $\begin{array}{c}\text { Min. } \\
\text { Demand } \\
\text { (MW) }\end{array}$ & $\begin{array}{c}\text { Max. } \\
\text { Demand } \\
\text { (MW) }\end{array}$ \\
\hline 1 & Risha & 0 & 33 & 33 \\
\hline 2 & AES CC & 59.85 & 210 & 410 \\
\hline 3 & $\begin{array}{c}\text { ACWA } \\
\text { CC }\end{array}$ & 60.09 & 210 & 360 \\
\hline 4 & $\begin{array}{c}\text { SAMRA } \\
4 \text { CC }\end{array}$ & 61.06 & 127.5 & 220 \\
\hline 5 & $\begin{array}{c}\text { SAMRA } \\
3 \text { CC }\end{array}$ & 61.06 & 192.5 & 420 \\
\hline 6 & $\begin{array}{c}\text { SAMRA } \\
1 \mathrm{CC}\end{array}$ & 61.06 & 210 & 310 \\
\hline 7 & QPC CC & 64.89 & 210 & 424 \\
\hline 8 & Wind & 72.79 & 0 & - \\
\hline 9 & PV & 79.94 & 0 & - \\
\hline 10 & Egypt & 52.79 & 0 & 150 \\
\hline 11 & IPP4 & 121.17 & 0 & 240 \\
\hline 12 & IPP3 & 231.04 & 0 & 570 \\
\hline
\end{tabular}

Units 1-7 are assumed to be operating at combined cycle (CC) and have lower costs, whereas both IPP3 and IPP4 are the most expensive power plants, where are composed of fast starting small generators of $15 \mathrm{MW}$ that are mainly used in peak times, where demand rises fast. Hence the main objective of the demand response is to reduce the usage of their units, thus reducing their cost liability on the GO. The dispatch model is based on Table 3 and selects power plants based on their minimum and maximum power based on the lowest cost. The Egyptian interconnection has lower priority as it is used as a backup to the main power plants, and renewable energy is based on availability. 


\subsection{Peak Period PEMD policy modeling}

As previously discussed, the PEMD is at the core of DR systems that correlates the change of electricity prices to the respective change in electrical demand. A constant price policy was proposed in the peak period that was selected from 4 PM to $8 \mathrm{PM}$. The base self-elasticity was approximated by the short-term price elasticity of Jordan's residential sector based on recent research at

$-0.0575[23]$. The residential PEMD base scenario can be seen in Table 3, where the base self-elasticity is -0.0575 and each cross-elasticity level at $25 \%$ of the selfelasticity represents the energy re-located from each hour in the peak period to the closest 4 hours outside of the peak period. The cross-elasticities in the peak period are all zeroes, as the price is constant in the peak period. Hence there is no incentive to re-locate energy consumption to hours within the peak period. All values of the elasticity matrix outside of the Matrix seen in Table 3 are assumed to be zero, as the prices don't change in those periods under this price policy.

Table 3 Base Scenario of the Residential PEMD of Jordan [7]

\begin{tabular}{|c|c|c|c|c|c|}
\hline Time $^{*}$ & $16: 00$ & $17: 00$ & $18: 00$ & $19: 00$ & $20: 00$ \\
\hline $12: 00$ & +0.0144 & 0 & 0 & 0 & 0 \\
\hline $13: 00$ & +0.0144 & +0.0144 & 0 & 0 & 0 \\
\hline $14: 00$ & +0.0144 & +0.0144 & +0.0144 & 0 & 0 \\
\hline $15: 00$ & +0.0144 & +0.0144 & +0.0144 & +0.0144 & 0 \\
\hline $16: 00$ & -0.0575 & 0 & 0 & 0 & 0 \\
\hline $17: 00$ & 0 & -0.0575 & 0 & 0 & 0 \\
\hline $18: 00$ & 0 & 0 & -0.0575 & 0 & 0 \\
\hline $19: 00$ & 0 & 0 & 0 & -0.0575 & 0 \\
\hline $20: 00$ & 0 & 0 & 0 & 0 & -0.0575 \\
\hline $21: 00$ & 0 & +0.0144 & +0.0144 & +0.0144 & +0.0144 \\
\hline $22: 00$ & 0 & 0 & +0.0144 & +0.0144 & +0.0144 \\
\hline $23: 00$ & 0 & 0 & 0 & +0.0144 & +0.0144 \\
\hline
\end{tabular}

Eight case scenarios are depicted in Table 4 based on Table 3 to capture different scenarios related to the selfelasticity and cross-elasticity behaviors of the residential sector.

[C5 -C8] have double the self-elasticity of [C1- C4], [C1, C2, C5, C6] assume the $100 \%$ of the energy from hours in the peak period is relocated to other hours, while their counterparts assume a 75\% shift scenario. In [C2, C4, C6, $\mathrm{C} 8$ ], the two hours furthest away of the 4 hours closest to the hour in the peak period have half the cross-elasticity value of the 2 hours nearest. More details on the establishment of the PEMD in Tables 3 and 4 can be found in the previous research[7].

Table 4 PEMD Case Scenarios[7]

\begin{tabular}{cccc}
\hline $\begin{array}{c}\text { Case } \\
\text { Scenarios }\end{array}$ & $\begin{array}{c}\text { Self- } \\
\text { Elasticity }\end{array}$ & $\begin{array}{c}\text { Cross Elasticity } \\
\text { L1 }\end{array}$ & Cross Elasticity -L2 \\
\hline C1 & & $-(-0.0575 / 4)$ & - \\
C2 & & $-(-0.0575 / 6)$ & $-2 \times(-0.0575 / 6)$ \\
C3 & -0.0575 & $-(0.75 \times(-0.0575)) / 4$ & - \\
C4 & & $-(0.75 \times(-0.0575)) / 6-2 \times(0.75 \times(-0.0575)) / 6)$ \\
\hline C5 & -0.115 & $-(-0.115 / 4)$ & - \\
\hline
\end{tabular}

\begin{tabular}{ccc}
\hline C6 & $-(-0.115 / 6)$ & $-2 \times(-0.115 / 6)$ \\
C7 & $-(0.75 \times(-0.115)) / 4$ & - \\
C8 & $-(0.75 \times(-0.115)) / 6$ & $-2 \times(0.75 \times(-0.115)) / 6)$ \\
\hline
\end{tabular}

\section{Results and Discussion}

The presented model has been applied for the winter month of December 2019 to show the impact of the proposed DR model for each day in the month. The bulksupply day and night prices for each distribution company (JEPCO, IDECO, and EDCO) are based on NEPCO's annual report [13], and their day-ahead residential demand is estimated at $32.4 \%, 5.08 \%$, and $9.98 \%$ of the total predicted demand respectively[7].

\section{Prediction performance for days with highest peak demand}

Fig. 5 -7 shows the performance of the day-ahead hourly prediction model for the days with the highest peak demand. It can be noticed from the figure that the model has very low MAPE errors between $1.68 \%-2.04 \%$ and that the peaks occur at $5 \mathrm{PM}$, which is captured by the peak period pricing policy.

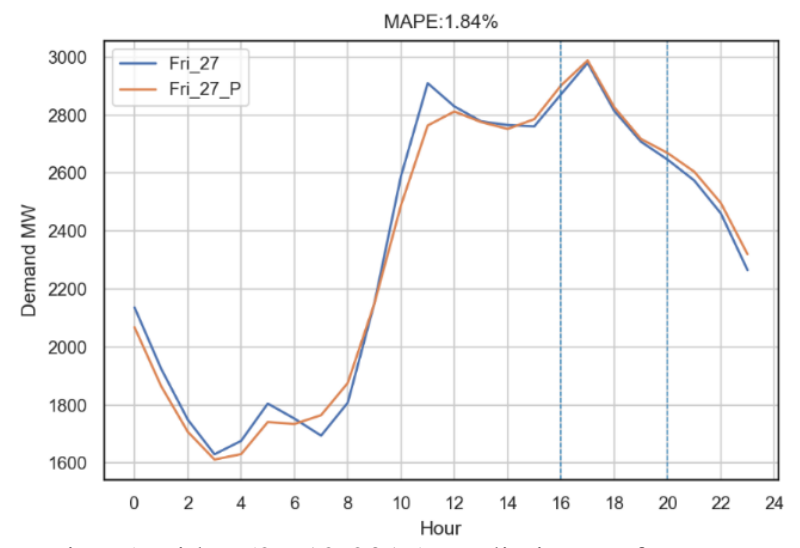

Fig. 5 Friday (27-12-2019) prediction performance

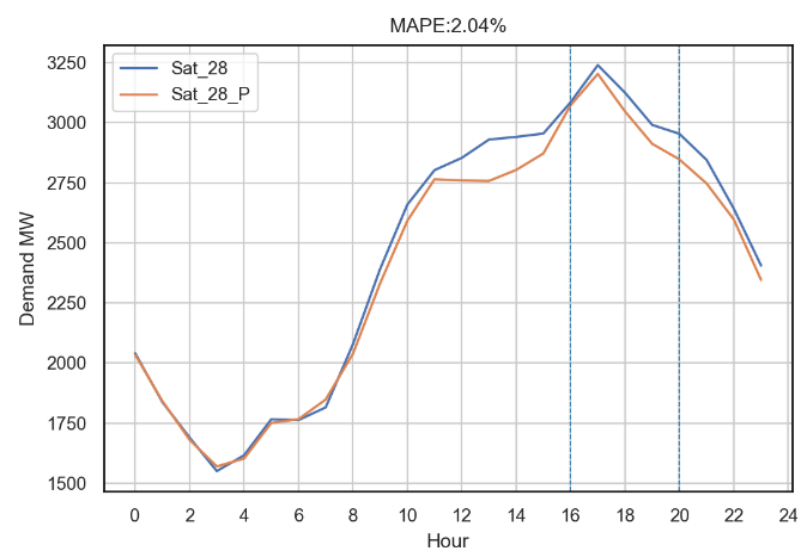

Fig. 6 Saturday (28-12-2019) prediction performance 


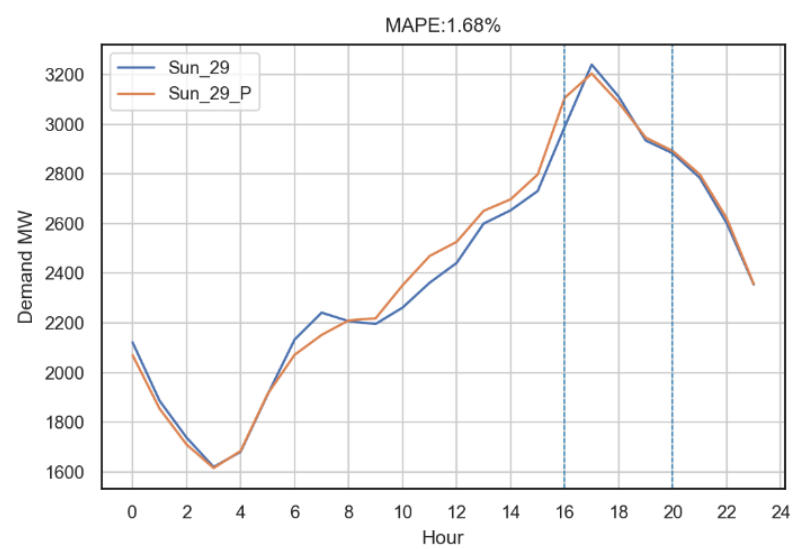

Fig. 7 Sunday (29-12-2019) prediction performance
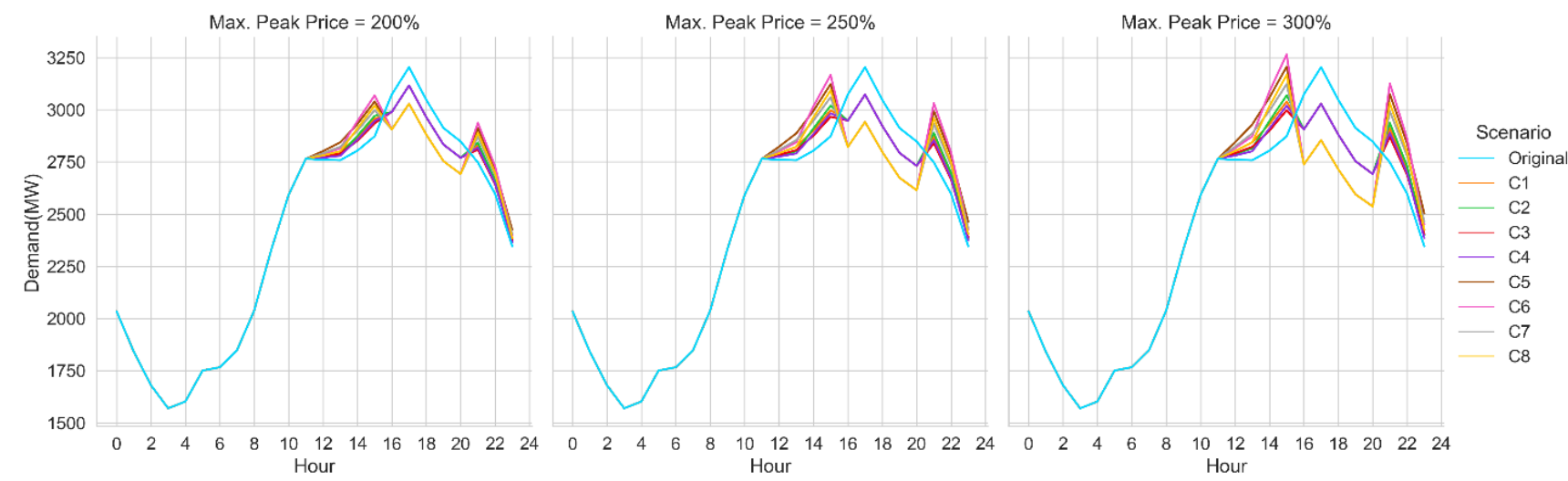

Fig. 8 DR-model output under different case scenarios (28-12-2019)

\subsection{Residential DR model analysis for the day with the highest peak demand.}

The results of applying the DR model to the day with the highest peak-demand being Saturday the $28^{\text {th }}$ of December is shown in Fig. 8. The figure shows the results based on the predicted demand of all the scenarios shown in Table 4 under 3 different maximum peak pricing ranges. The profit maximization model always selects the maximum price for the peak period up to a $300 \%$ increase in price. [C1-C4] showed lower peak reduction as they had lower self-elasticity than [C5-C8], although their new peaks created around the peak period were lower since less demand was shifted. Hence, the more demand shifted, the higher the chance of new peak forming, such as the case of $\mathrm{C} 6$ at $300 \%$ peak period price, where the new peak formed was higher than the original peak. It can

also be noticed that with the increase in price, while the peak reduction increases, the chances for the new peak to form also increase; hence, careful selection of the maximum peak period pricing should be carried out to find the achieves the optimal demand curve as per operational goals. Fig. 9 shows the ranges of peak demand reduction for each case scenario of the PEMD and the peak period pricing, where it can be noticed that a minimum peak reduction of $4.217 \%$ from all the case scenarios and the best peak reduction being $5.458 \%$. Hence, even in the worst-case scenario being C6, where the self-elasticity is highest, $100 \%$ of the reduced demand is shifted, and the shifted demand has double the weight for the two hours closest to the peak period, by selecting the correct price range, a good peak reduction can be achieved.

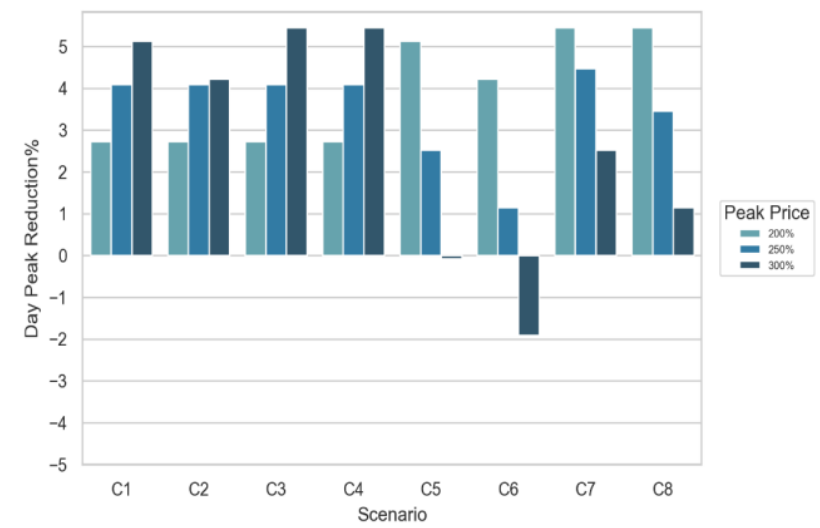

Fig. 9 Peak Reduction ranges (28-12-2019)

Fig. 10 shows the ranges of cost savings that can be achieved when the demand shifted from the peak periods results in lower purchasing power from IPP3 and IPP4 that are expensive. It can be observed that $\mathrm{C} 7$ and $\mathrm{C} 8 \mathrm{had}$ the highest cost-saving potential, with $\mathrm{C} 7$ being $220,581 \$$ and the minimum cost saving was observed at $43,774 \$$ for $\mathrm{C} 2$. C7 showed the most elevated cost saving due to the fact that it is a high self-elasticity scenario, where more peak demand is reduced, only $75 \%$ of the demand reduced is shifted with equal weights; hence, more demand can be reduced without creating higher peaks surrounding the peak period. It can also be noticed for $\mathrm{C} 7$ in Fig. 9 and 10 that at $300 \%$ of the price, even if the peak reduction was lower than at $200 \%$, more cost-saving was achieved. This is due to the fact that the demand shifted from the peak period had more weight in terms of costsaving, even if less peak reduction was achieved. 


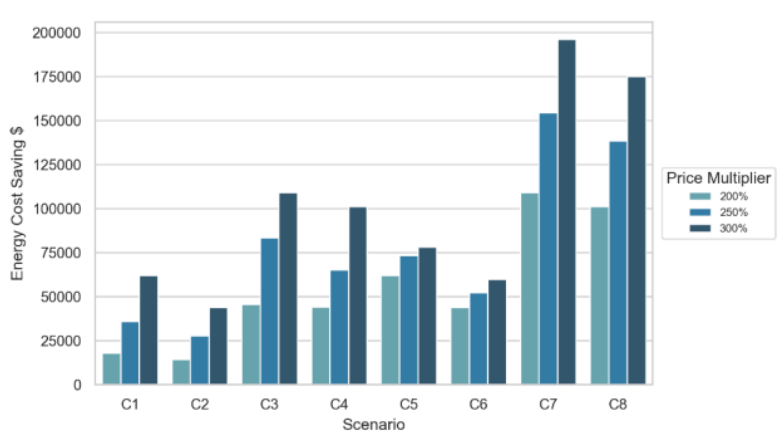

Fig. 10 Energy Cost Saving (28-12-2019)

\subsection{Day-ahead Residential DR model analysis for December 2019}

The results for applying the DR model for the whole month of December are shown in Fig. 11 -13 in terms of peak reduction, load factor improvement and costsaving, with the vertical lines indicating the weekends.

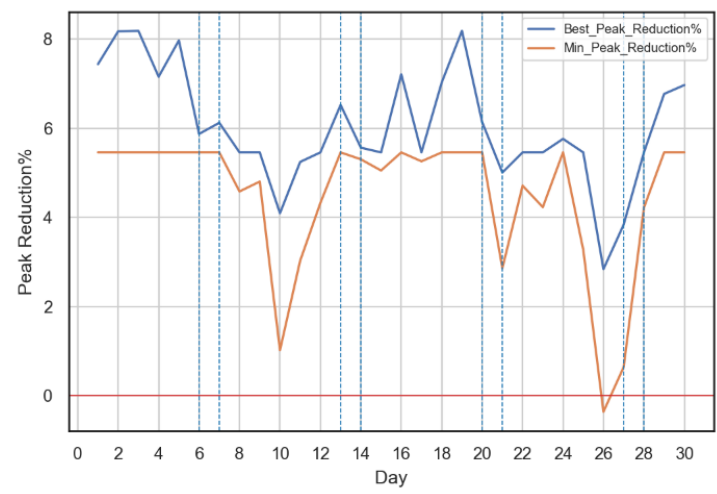

Fig. 11 Peak Reduction for December 2019

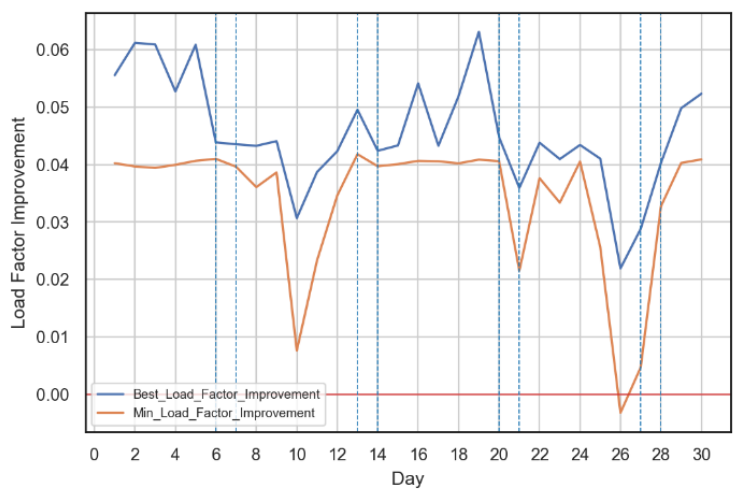

Fig. 12 Load factor improvement for December 2019



Fig. 13 Cost saving for December 2019
The "best" indicates that case scenario that had the very highest result such as (C7-300\%) in Fig. 10, while "Min" depicts the minimum achievable result out of all the case scenarios such as (C2-300\%) from the same figure, but not the very worst result. In terms of peak reduction observed in Fig. 11, the best results had a maximum potential of $8.19 \%$ with an average of $6.04 \%$, while the minimum results had a maximum of $5.46 \%$ and an average of $4.49 \%$. It could also be noticed that there were only 4 days in the month where the model and peak period price policy showed low performance in terms of the minimum achievable results, which is due to the demand curve behavior in those days. The load factor improvement results shown in Fig. 12 had an average of 0.05 and 0.034 for the best and minimum results, respectively, and followed the same trend as Fig.11. The load factors are calculated by dividing the average demand of the day by its peak, where the closer they are to each other the better, approaching 1 . As for the costsaving results depicted by Fig. 13, the average for the best and minimum results were 154,890 \$ and 64,263 \$, respectively. The highest best cost-saving was observed at $265,411 \$$ Saturday the $21^{\text {st }}$, where it can be observed that most Saturdays on the $7^{\text {th }}, 14^{\text {th }}, 21^{\text {st, }}$ and $28^{\text {th }}$ showed high-cost saving potential consistently, especially in relevance to Fridays that showed the lowest cost-saving potential.

\subsection{Predicted DR model impact vs. Real impact}

As the model results are based on the predicted dayahead demands, which are very close to the real demands as shown in section 3.1, the real impacts of the DR vs the predicted impacts for the cost savings are shown in Fig 14.

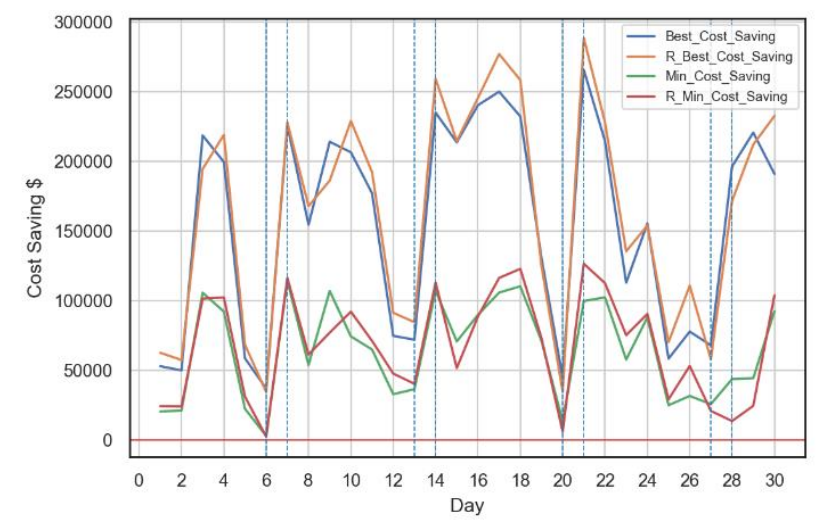

Fig. 14 Real vs Predicted DR impacts

The difference in the results is based on the accuracy of the prediction, which shows the importance of having an accurate model with high prediction performance to correctly predict the day-ahead demand and provide an accurate prediction to the selected day-ahead peakprices.

\section{Conclusion}

This research presented a detailed analysis of the impacts of a day-ahead DR model on Jordan's residential sector in the winter season, depicting the highest demands. The model results showed that for December 2019, the average minimum peak reduction and cost savings 
predicted by the model were $4.49 \%$ and $64,263 \$$ per day, respectively, with the highest potential peak reduction predicted at $8.19 \%$ and cost-saving of $265,411 \$$. The results indicate the significant opportunity to apply residential DR for the Jordanian power sector to mitigate the effects of the high ramping peak demands and achieve cost reduction for the GO. The results also showed the importance of having accurate predictions for the day-ahead demand, to achieve an optimal DR system.

\section{REFERENCES}

[1] IEA, "Global Energy and CO2 Status Report," Oecd-Iea, no. March, p. 15, 2018, [Online]. Available: https://www.iea.org/publications/freepublications/public ation/GECO2017.pdf. (accessed 7.05.2021).

[2] G. Tsourapas, "The Syrian Refugee Crisis and Foreign Policy Decision-Making in Jordan, Lebanon, and Turkey," J. Glob. Secur. Stud., vol. 4, no. 4, pp. 464 481, 2019, doi: 10.1093/jogss/ogz016.

[3] G. Abu-Rumman, A. I. Khdair, and S. I. Khdair, "Current status and future investment potential in renewable energy in Jordan: An overview," Heliyon, vol. 6, no. 2, p. e03346, 2020, doi: 10.1016/j.heliyon.2020.e03346.

[4] W. Bank, "Implementation Completion And Results Report (Ibrd-85300) On Ibrd Loans With The Concessional Financing Facility Support In The Aggregate Amount Of Us $\$ 500$ Million To The Hashemite Kingdom Of Jordan For The First And Second Programmatic Energy And Water Se," 2018. [Online]. Available: http://documents1.worldbank.org/curated/en/222301546 546705732/pdf/icr00004657-12282018-

636818041906584165.pdf. (accessed on 13.04.2021).

[5] G. Abu-Rumman, A. I. Khdair, and S. I. Khdair, "Current status and future investment potential in renewable energy in Jordan: An overview," Heliyon, vol. 6, no. 2, p. e03346, 2020, doi: 10.1016/j.heliyon.2020.e03346.

[6] J. Ma, V. Silva, R. Belhomme, D. S. Kirschen, and L. F. Ochoa, "Evaluating and Planning Flexibility in Sustainable Power Systems," IEEE Trans. Sustain. Energy, vol. 4, no. 1, pp. 200-209, 2013, doi: 10.1109/TSTE.2012.2212471.

[7] A. Shaqour, H. Farzaneh, and H. Almogdady, "Day-Ahead Residential Electricity Demand Response Model Based on Deep Neural Networks for Peak Demand Reduction in the Jordanian Power Sector," Applied Sciences, vol. 11, no. 14. 2021, doi: 10.3390/app11146626.

[8] H. Farzaneh, L. Malehmirchegini, A. Bejan, T. Afolabi, A. Mulumba, and P. P. Daka, "Artificial intelligence evolution in smart buildings for energy efficiency," Appl. Sci., vol. 11, no. 2, pp. 1-26, 2021, doi: 10.3390/app11020763.

[9] D. S. Kirschen, A. Rosso, J. Ma, and L. F. Ochoa, "Flexibility from the demand side," in 2012 IEEE Power and Energy Society General Meeting, 2012, pp. 1-6, doi: 10.1109/PESGM.2012.6344828.

[10] P. D. Lund, J. Lindgren, J. Mikkola, and J. Salpakari, "Review of energy system flexibility measures to enable high levels of variable renewable electricity," Renew. Sustain. Energy Rev., vol. 45, pp. 785-807, 2015, doi: 10.1016/j.rser.2015.01.057.
[11] "Zero Emission Buildings and Challenges in Japan," Int. Exch. Innov. Conf. Eng. \&Sciences, pp. 96101, 2018, doi: 10.15017/1961295.

[12] S. Murtyas, R. Anggi, and M. Ridwan, "Adapting Buildings for Climate Change: Will Indonesian Traditional Houses Shift to Zero Energy Buildings ?," Proc. Int. Exch. Innov. Conf. Eng. Sci., pp. 56-59, 2018.

[13] NEPCO- National Electric Power Company, "Annual Report 2019 NEPCO," 2019. [Online]. Available:

https://www.nepco.com.jo/store/DOCS/web/2019_en.p df. (accessed 13.04.2021).

[14] N. Tawalbeh, H. M. Abusamaha, and A. AlSalaymeh, "Demand side management and its possibilities in jordan," J. Ecol. Eng., vol. 21, no. 1, pp. 29-33, 2020, doi: 10.12911/22998993/113417.

[15] H. Jarada and M. S. Ashhab, "Energy savings in the Jordanian residential sector," Jordan J. Mech. Ind. Eng., vol. 11, no. 1, pp. 51-59, 2017.

[16] V. Di Cosmo, S. Lyons, and A. Nolan, "Estimating the impact of time-of-use pricing on irish electricity demand," Energy J., vol. 35, no. 2, pp. 117136, 2014, doi: 10.5547/01956574.35.2.6.

[17] Z. Wang, U. Munawar, and R. Paranjape, "Stochastic Optimization for Residential Demand Response with Unit Commitment and Time of Use," IEEE Trans. Ind. Appl., vol. 57, no. 2, pp. 1767-1778, 2021, doi: 10.1109/TIA.2020.3048643.

[18] E. Mengelkamp, S. Bose, E. Kremers, J. Eberbach, B. Hoffmann, and C. Weinhardt, "Increasing the efficiency of local energy markets through residential demand response," Energy Informatics, vol. 1, no. 1, pp. 1-18, 2018, doi: 10.1186/s42162-018-0017-3.

[19] J. H. Yoon, R. Bladick, and A. Novoselac, "Demand response for residential buildings based on dynamic price of electricity," Energy Build., vol. 80, pp. 531-541, 2014, doi: 10.1016/j.enbuild.2014.05.002.

[20] Japan International Cooperation Agency (JICA), "Project for the Study on the Electricity Sector Master Plan in the Hashemite Kingdom of Jordan Final Report," no. February, 2017, [Online]. Available: https://openjicareport.jica.go.jp/pdf/12283693_01.pdf.

[21] S. Ryu, J. Noh, and H. Kim, "Deep neural network based demand side short term load forecasting," Energies, vol. 10, no. 1, pp. 1-20, 2017, doi: 10.3390/en10010003.

[22] M. Leshno, V. Y. Lin, A. Pinkus, and S. Schocken, "Multilayer feedforward networks with a nonpolynomial activation function can approximate any function," Neural Networks, vol. 6, no. 6, pp. 861-867, 1993, doi: 10.1016/S0893-6080(05)80131-5.

[23] S. Ajlouni, "Price and Income Elasticities of Residential Demand for Electricity in Jordan : An ARDL Bounds Testing Approach to Cointegration," Dirasat Adm. Sci., vol. 43, no. 1, pp. 335-349, 2016, doi: $10.12816 / 0028467$. 